\title{
AUTOMATIC DAMAGE DETECTION FOR SENSITIVE CULTURAL HERITAGE SITES
}

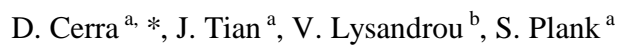 \\ ${ }^{a}$ German Aerospace Center (DLR), Earth Observation Center (EOC), 82234 Weßling, Germany \\ (daniele.cerra, jiaojiao.tian, simon.plank)@dlr.de
}

${ }^{\text {b }}$ Cyprus University of Technology, Department of Civil Engineering and Geomatics, Archaeology and Cultural Heritage section
vasiliki.lysandrou@cut.ac.cy

Commission V, WG V/2

KEY WORDS: Cultural heritage, change detection

\begin{abstract}
:
The intentional damages to local Cultural Heritage sites carried out in recent months by the Islamic State (IS) have received wide coverage from the media worldwide. Earth Observation data is an important tool to assess these damages in such non-accessible areas: If a fast response is desired, automated image processing techniques would be needed to speed up the analysis. This paper shows the first results of applying fast and robust change detection techniques to sensitive areas. A map highlighting potentially damaged buildings is derived, which could help experts at timely assessing the damages to the Cultural Heritage sites in the observed images.
\end{abstract}

\section{INTRODUCTION}

The significance of remote sensing in "exploration, identification and documentation and in monitoring archaeological heritage in the living landscape" has been vigorously highlighted during the $11^{\text {th }}$ Europae Archaeologiae Consilium Heritage Management Symposium in 2010 (Cowley, 2011). Remote sensing applications for the aforementioned purposes bear a twofold utility, since from one hand they consist in distant non-destructive techniques and on the other hand they cover broader areas at the same time, moving from the monument level to that of landscape coverage.

When the Islamic State (IS) was rumored in the media to have destroyed cultural heritage sites in Iraq and Syria - Nimrud and Palmyra - officials could not reach the areas in person to confirm the damage. Therefore, the European Space Imaging (EUSI) supplied the Orient Department of the German Archaeological Institute (DAI) very high resolution (VHR) imagery to safely assess the situation on the ground. The images have been processed and analyzed by remote sensing experts of the German Aerospace Center (DLR). A visual analysis confirmed the destruction of several sites as claimed by the IS, such as the temple of Bel and several ancient tower tombs within Palmyra's Valley of the Tombs (UNESCO, 1972).

If change detection for damage assessment is performed by visual analysis on large areas, it becomes a difficult and timeconsuming activity, and the knowledge acquired from its results could be incomplete. In the specific, damaged areas could remain undetected for an observer, if the time available for the analysis is limited.

In this paper we propose to apply a change detection algorithm to solve this problem, automatically deriving maps in which the areas suspected of having suffered damages are highlighted. We choose a robust detector in order to obtain a reliable change map if the images present co-registration errors or geometric distortions caused by different acquisition angles. The spots presenting the highest changes are highlighted to rapidly provide a potential set of sensitive areas on which a more detailed analysis should be carried out.

The paper is structured as follows. Section 2 introduces the archeological site of Palmyra and some of the relevant monuments which suffered damages from terrorist activities. Section 3 reports the adopted change detection workflow, while experimental results are described in Section 4. We conclude in Section 5 .

\section{CASE STUDY}

The present paper focuses on a part of the large archaeological site of Palmyra situated in the Syrian Desert north-east of Damascus. The archaeological vestiges of the ancient Roman city are listed in the UNESCO World Heritage since 1980, while from 2013 until today the site has been added to the List of World Heritage in Danger (Article 11 (4) of the World Heritage Convention) (UNESCO, 1972). The monumental ruins belong to an ancient city flourished between the $1^{\text {st }}$ and $3^{\text {rd }}$ century A.D., as part of the Roman Empire. Due to its geographical position, Palmyra was during antiquity a major trading center and bridging route between Mediterranean and Euphrates.

Amongst the first archaeological excavation missions undertaken in the area were the monuments under consideration in this paper, namely the Sanctuary of Bel (Starcky and Munajjed, 1960; Seyrig, 1936). The Temple of Bel is situated in the south-eastern part of the walled city. The Temple dates back to the Hellenistic period, and received several architectural modifications throughout the first two centuries A.D. drawing thus the attention of scholars to the multiple architectural details of the monument, alongside its chronological evolution. During the $12^{\text {th }}$ century, its monumental propylaeum entrance was transformed into a fortified bastion. The Temple of Bel most probably comprises the first building of the sanctuary and it is located approximately in its center. From a Palmyrene inscription on the pedestal of the statue we read that Lishamsh

\footnotetext{
* Corresponding author
} 
to whom the statue belonged, has dedicated the Temple of the Gods Bel, Iarhibol and Aglibol in its sanctuaries in 32 A.D. (Cantineu, 1934, UNESCO, 1972). The Semitic's god Bel worship was dominant in the Palmyrene religious cult (Danti, 2001).
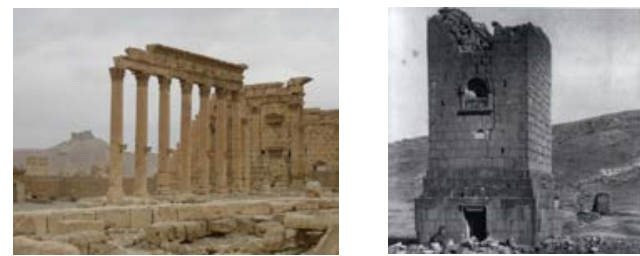

Figure 1. Temple of Bel (left) and tower tomb of Elahbel (right). Photos taken by T. Paulette in 2005 and by Wolfe Expedition in 1885, respectively.

Outside the walls of the city its ancient necropolis is to be found. Here under examination is the western necropolis, better known as Valley of the Tombs. This cemetery contains some impressive built tombs belonging to the architectural type of the tower tombs (e.g. Tower tomb of Elahbel, Tower tomb of Atenatan, Tower tomb of Julius Aurelius Bolma, Tower tomb of Kithoth Tomasu). These tombs were erected during the $1^{\text {st }}$ and $2^{\text {nd }}$ centuries A.D. to serve the wealthy inhabitants of the city, and their existence and preservation alongside the study of the burial customs to be detected within the tombs, consist of an important source of information for the lives of the elite class of that time. The tower tombs contained rich decoration such as wall paintings, funerary sculptures, inscriptions, and sarcophagi. Photographic documentation of the described sites is reported in Fig. 1.

\section{ROBUST CHANGE DETECTION}

The aim of a change detection algorithm is to provide a map of changes when given in input two or more images acquired at different times over the same area. For the applications described in this paper, the desired output should highlight the locations of monuments which suffered damages or changes in a short time span.

Nevertheless, automatic change detection techniques may be difficult to apply in practice. For example, the differences between pre- and post-event images may be difficult to obtain in a reliable way if the acquisition dates of the two images are too far away. Even if this is not the case, a pixel-based analysis is difficult to carry out even after an accurate co-registration step, as often, no high resolution Digital Surface Model (DSM) is available. In this case, images may exhibit orthorectification errors, and the differences in view angle introduce in turn pronounced geometric distortions.

Many approaches have been proposed to solve this problem, such as region-based or grid-based comparison (Blaschke, 2010; Im et al., 2008). For a fast comparison, Robust Difference (RD) has been initially proposed by Castilla et al. (2009) and successfully applied to compare DSMs (Tian et al., 2014). The $\mathrm{RD}$ distance is based on the assumption that the corresponding pixels of two images show the minimum intensity value differences within a small region, especially when the images were captured by the same sensor.

A RD between the pre-disaster image $X$ and a post-disaster image $Y$ for a pixel at coordinates $(i, j)$ can be defined as the minimum of differences computed between the pixel $Y(i, j)$ in the post-disaster image and a certain neighborhood (with window size $2 w+1)$ of the pixel $X(i, j)$ in the pre-disaster image $X$. The $\mathrm{RD}(i, j)$ relative to the pixel $(i, j)$ are defined as:

$$
R D(i, j)=\min _{p, q}\{\operatorname{abs}(Y(i, j)-X(p, q))\}
$$

$$
\begin{aligned}
& \text { where } \quad \begin{array}{l}
i, j=\text { image coordinates } \\
w=\text { maximum distance from } i, j \\
(p, q) \in[i-w, j+w]=\text { coordinates of pixels in the } \\
\text { neighbourhood centered around } i, j
\end{array}
\end{aligned}
$$

This means that only the minimum value of the absolute difference is taken into account, all within the defined window size, which should be adjusted based on the scale of the occurred changes. Typically used window sizes are square and range from $3 \times 3$ up to $11 \times 11$ pixels depending on the amount of geometric distortions caused by different acquisition angles and differences between the original spatial resolution of the two available images. As the input images are multispectral, the RDs are computed for each channel separately; subsequently, their chi-distances are summed up to produce the final change map.

The RD is by definition robust to geometric distortions caused by differences in the terrain and to errors introduced in the coregistration step. To produce a final change map, a threshold is applied selecting all pixels with $R D>1200$. Morphological filtering (opening and closing) is subsequently applied to the binary thresholded image to produce the final results.

\section{EXPERIMENTS}

Figs. 2 and 3 report the subsets of two WorldView-2 datasets acquired outside the city center of Palmyra, Syria, on the $27^{\text {th }}$ of August and $2^{\text {nd }}$ of September 2015, respectively. Henceforth we refer to these two dates as as $t_{1}$ and $t_{2}$.

At time $t_{1}$ the Islamic State (IS) had already destroyed several Cultural Heritage $(\mathrm{CH})$ sites in the area, namely the tower tombs of Atenaten, Iamliku, and the Banai family, the temple of Baalshamin, and the Abu Behaeddine shrine. Between $t_{1}$ and $t_{2}$, other tower tombs and the temple of Bel have been damaged. In the figures the temple of Bel is located in the bottom right, while the tower tombs are scattered in the upper left part of the image.

The available images exhibit some pronounced orthorectification errors, as no high resolution Digital Surface Model (DSM) is available. We are therefore in one of the cases for which the RD described in previous section may yield more reliable results.

In a first step the co-registration of the images has been refined by automatically deriving 1000 Ground Control Points by matching of Scale Invariant Feature Transform features (Löwe, 2004) between the two images, and by warping the image acquired at time $t_{1}$ using as reference the image acquired at time $t_{2}$.

The absolute value of the $\mathrm{RD}$, representing the confidence that a real change has taken place for a given pixel, is reported in Fig. 4. To produce a change map, a thresholded version of the image has undergone a filtering through three cycles of morphological opening and closing. The structuring element of choice was a disc of size 3 , corresponding to a $3 \times 3$ square window filled with ones, with zeros in the corners.

Results are reported as red areas in Fig. 5. All of the tower tombs in the image destroyed by the IS between $t_{1}$ and $t_{2}$ are 
correctly detected from the algorithm, well agreeing with the report on the situation in Palmyra in (Cuneo, 2015). On the right, the destruction of the central part and the eastern wall of the temple of Bel are also detected. The only false alarm is given in the lower central part of the image due to an artifact in the dataset acquired at time $t_{2}$ (see Fig. 6).

\section{CONCLUSIONS}

The importance of remotely sensed earth observation data has been widely acknowledged in recent years. The change detection methodology proposed in this paper is aimed at increasing the timeliness for the production of detailed damage assessment maps in $\mathrm{CH}$ sites in sensible areas providing the image analysts with a map of potentially damaged sites. As the process is robust and fast, it would represent a valuable, cost and time efficient tool in the hands of professionals dealing with $\mathrm{CH}$ management and monitoring, as important information in sensitive areas could be promptly derived, once the post-change image is available and co-registered to the pre-change acquisition.

The proposed method could be applied in similar cases to inaccessible areas of war conflict in order to obtain a rapid detection and documentation of the damages. Furthermore, the methodology is arguably appropriate for long term monitoring of cultural heritage sites in terms of their inspection against natural and anthropogenic hazards.

The methodological approach here presented could thus be imported in the general planning related to the development of risk-preparedness strategies for cultural heritage sites, as well as for the disaster-response planning. The development of strategy for the protection of $\mathrm{CH}$ in the event of armed conflict request regular monitoring and inspection of the condition of significant $\mathrm{CH}$ sites, to be undertaken as a basis of follow-up actions further underlining the need for salvage recording or documentation of threaten or damaged cultural property (Stovel, 1998).

In the future, the method could be enhanced by integrating the analysis of texture parameters extracted from the images, as destroyed sites usually appear as areas where high frequencies are predominant.

\section{REFERENCES}

Blaschke, T., 2010. "Object based image analysis for remote sensing”, ISPRS Journal of Photogrammetry and Remote Sensing vol. 65, no. 1, pp. 2-16.
J. Cantineau, 1934. Inventaire des Inscriptions de Palmyre fasc. IX: le sanctuaire de Bêl, Damascus Museum.

G. Castilla, R. H. Guthrie, G. J. Hey, 2009. "The land-cover change mapper (LCM) and its application to timber harvest monitoring in western Canada”, Photogrammetric Engineering \& Remote Sensing, vol. 75, no. 8, pp. 941-950.

United Nations Educational, Scientific and Cultural Organisation (UNESCO), Convention concerning the protection of the world cultural and natural heritage, Adopted by the General Conference at its seventeenth session Paris, 16 november 1972.

D. C. Cowley (ed.), 2011. Remote Sensing for Archaeological Heritage Management, EAC Occasional Paper No. 5, Budapest.

A. Cuneo, S. Penacho, and L. Barnes Gordon, 2015. "Special Report: Update on the Situation in Palmyra", 3 September 2015. Available online (accessed 29.03.2016) at: http://www.asor-syrianheritage.org/special-report-update-onthe-situation-in-palmyra/

Danti M., "Palmyrene funerary sculptures at Penn”, Expedition 43 no.3, 2001.

Im, J., Jensen, J. R., Tullis, J. A., 2008. “Object based change detection using correlation image analysis and image segmentation”, International Journal of Remote Sensing, vol. 29, no. 2, pp. 399-423.

D. Löwe, 2004. "Distinctive image features from scale-invariant keypoints”, International journal of computer vision, vol. 60, no. 2, pp. $91-110$.

S. Plank, G. Strunz, M. van Ess, P. Richardson, 2015. "Monitoring of cultural heritage sites using VHR earth observation data", WorldView Global Alliance - User Conference 2015, Munich (Germany), 13.-14.Oct. 2015.

Seyrig H., Antiquités Syriennes, vol. 3, Paris 1936-1946.

Starcky J. and Munajjed S., Palmyra, The bride of the desert, Damascus 1960.

Stovel H., Risk Preparedness: A management manual for World Cultural Heritage, Rome 1998.

J. Tian, S. Cui, P. Reinartz, 2014. "Building change detection based on satellite stereo imagery and digital surface models", IEEE Transactions on Geoscience and Remote Sensing, vol. 52, no. 1, pp. 406-417. 


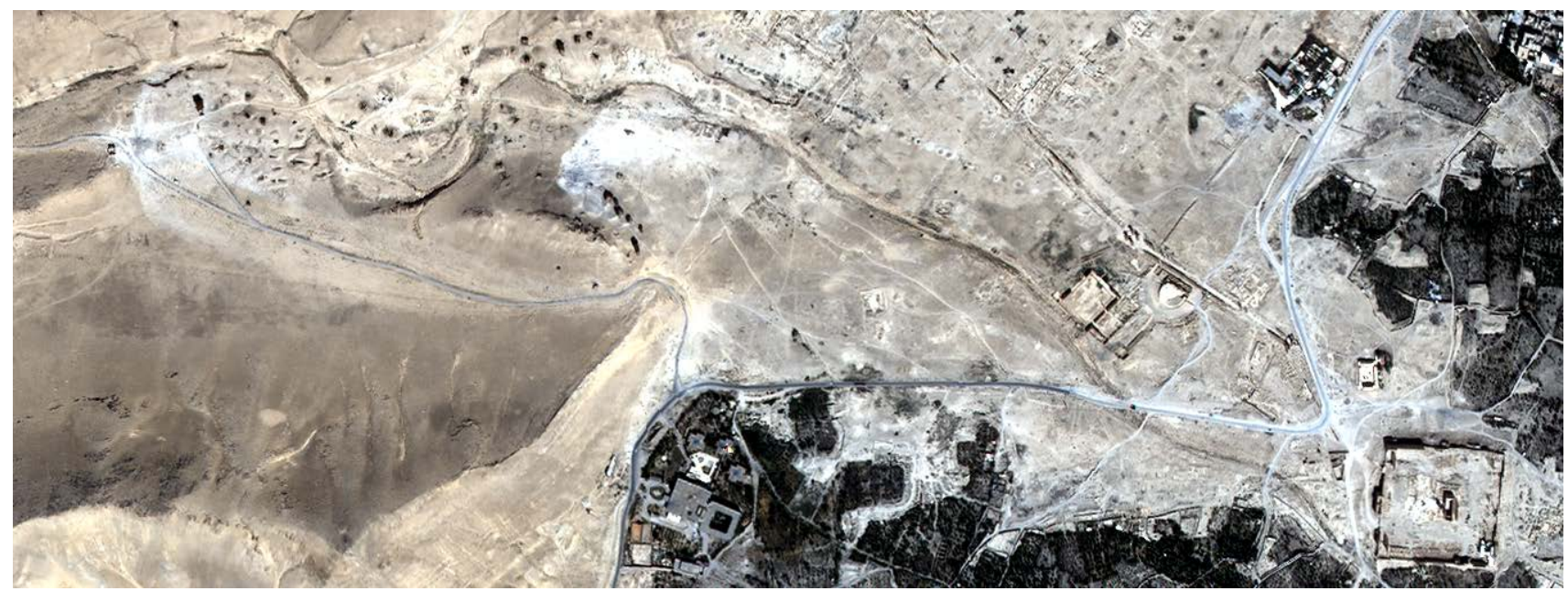

Figure 2. Subset of the WorldView-2 image acquired on the $27^{\text {th }}$ of August 2015 (CEuropean Space Imaging / DigitalGlobe).

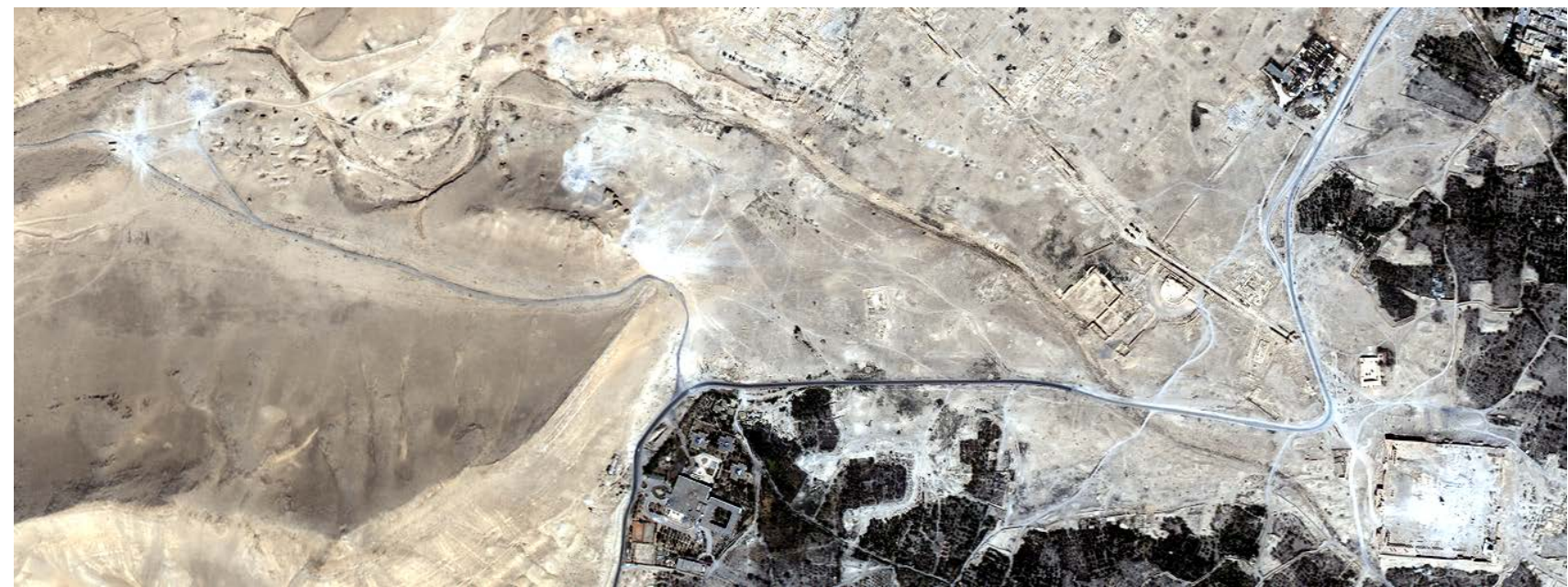

Figure 3. Subset of the WorldView-2 image acquired on the $2^{\text {nd }}$ of September 2015 (CEuropean Space Imaging / DigitalGlobe).

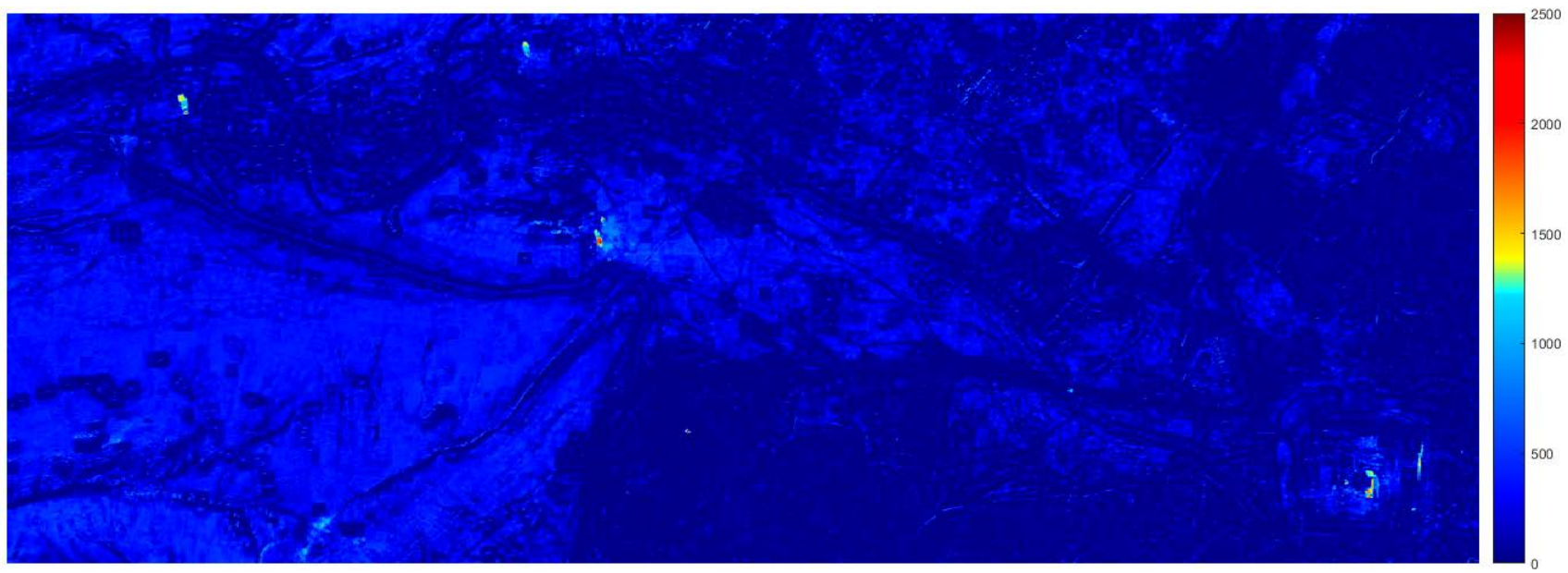

Figure 4. Robust change map 


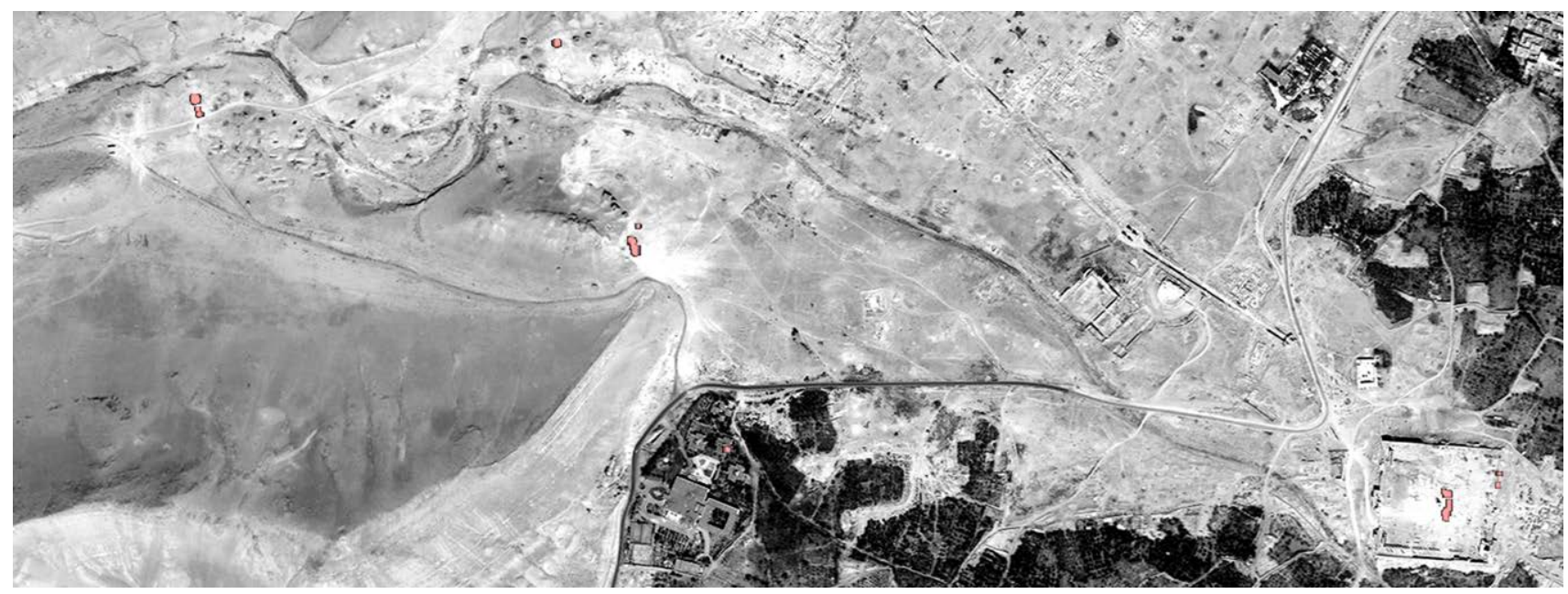

Figure 5. Post-processed change map overlaid on the $2^{\text {nd }}$ of September 2015 WorldView-2 image (CEuropean Space Imaging / DigitalGlobe).

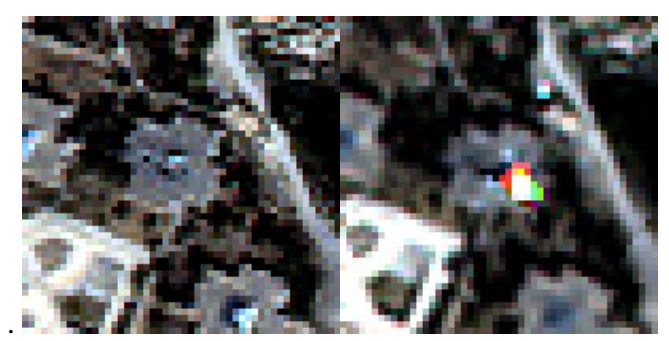

Figure 6. Figure 5. Image details for the two images related to the only false alarm in the lower center of Fig. 5. This is due to an artefact present in the second image (CEuropean Space Imaging / DigitalGlobe). 